\title{
CAPÍTULO 10: AVALIAÇÃO DA TOXICIDADE IN VITRO DO EXTRATO ENZIMÁTICO DO LÁTEX DA EUPHORBIA MILII PARA PROCESSAMENTO DE ALIMENTOS
}

\author{
CAPÍTULO 10: EVALUACIÓN DE LA TOXICIDAD IN VITRO DEL EXTRACTO \\ ENZIMÁTICO DE EUPHORBIA MILII LATEX PARA EL PROCESAMIENTO DE \\ ALIMENTOS
}

\section{CHAPTER 10: IN VITRO TOXICITY ASSESSMENT OF EUPHORBIA MILII' LATEX ENZYMATIC EXTRACT FOR FOOD PROCESSING}

\author{
Iris Barbosa de Souza1; Graziela Domingues Almeida Lima²; Erika Valente de Medeiros³ Keila Aparecida Moreira4; \\ Ana Lucia Porto Figueiredo 5
}

DOI: https://doi.org/10.31692/978-65-88970-19-5.146-158.

\begin{abstract}
RESUMO
A importância das plantas tóxicas não está somente nos riscos que possam causar, mas também dos benefícios que podem proporcionar. Entre essas, o látex de E. milii que apresenta atividade moluscicida, mas também potencial para uso farmacológico e no processamento de alimentos. Incentivando assim a avaliação da sua toxicidade através de ensaios que são necessários principalmente quando se trata de investigações toxicológicas preliminares em atendimento aos princípios éticos e econômicos. Nesse sentido, o presente estudo objetivou avaliar a toxicidade in vitro do látex de E. milii usando como modelo a Artemia salina e a avaliação de citotoxicidade com eritrócitos humanos, linhagem Vero e macrófagos. O látex de E. milii foi extraído e diluído (1/1) em solução tampão fosfato de sódio $1 \mathrm{M}, \mathrm{pH} 7,0$ foi centrifugado $\left(5000 \mathrm{~g}, 4{ }^{\circ} \mathrm{C}\right.$ por $30 \mathrm{~min}$.) e o produto final passou por processo de liofilização. No ensaio de toxicidade frente a A. salina foram testadas o látex liofilizado nas concentrações de 3,5; 7,$0 ; 10,5 ; 14 ; 21 ; 28$ e $35 \mathrm{mg} / \mathrm{mL}$ de água do mar esterilizada. No teste de citotoxicidade o látex foi dialisado antes da liofilização e diluído nas mesmas concentrações em soro fisiológico. A toxicidade do látex no ensaio com $A$. salina foi estimada pela $\mathrm{CL}_{50}$ usando o Probit e o percentual de viabilidade celular foi determinado para os resultados de citotoxicidade e avaliado pelo teste de Dunnett. Após 24 horas de exposição ao látex, a $\mathrm{CL}_{50}$ das larvas de A. salina foi estimada em $64,22 \mathrm{mg} / \mathrm{mL}$. O látex de $E$. milii manteve a viabilidade das células sem causar hemólise dos eritrócitos, teve ligeira diminuição das células da linhagem Vero $(10,33 \%)$ na concentração de $35 \mathrm{mg} / \mathrm{mL}$ e reduziu a viabilidade de macrófagos $(26,34-45,53 \%)$ nas concentrações usadas no ensaio. Os testes preliminares in vitro revelaram que o látex de E. mili não apresenta risco de toxicidade, mas investigações complementares são necessárias principalmente para uso na área da saúde e em alimentos.
\end{abstract}

Palavras-Chave: citotoxidade, toxicidade, viabilidade celular, Euphorbia milii, Artemia salina.

\section{RESUMEN}

La importancia de las plantas tóxicas no está solamente en los riesgos que éstas pueden ocasionar, sino también en los beneficios que pueden brindar. Entre estos, el látex de E. milii que presenta actividad molusquicida, además de potencial para el uso farmacológico y en el procesamiento de alimentos. Incentivando, por lo tanto, la evaluación de su toxicidad a través de ensayos que son necesarios principalmente cuando se trata de investigaciones toxicológicas preliminares en cumplimiento de principios éticos y económicos. En este sentido, el presente estudio tuvo como objetivo evaluar la toxicidad in vitro del látex de E. milii utilizando Artemia salina como modelo, y la evaluación de la citotoxicidad con eritrocitos humanos, linaje Vero y macrófagos. Se extrajo látex de E. milii y se diluyó (1/1) en una solución tampón de fosfato de sodio $1 \mathrm{M}$, se centrifugó a pH 7,0 (5000 g, $4^{\circ} \mathrm{C}$ durante $30 \mathrm{~min}$ ) y el producto final se sometió a un proceso de liofilización. En el ensayo de toxicidad ante A. salina, se probó látex liofilizado a concentraciones de 3,5; 7,0;10,5;14;21;28 y $35 \mathrm{mg} / \mathrm{mL}$ de agua marina estéril. En la prueba de citotoxicidad, el látex se dializó antes de la liofilización y se diluyó a las mismas concentraciones en suero fisiológico. La toxicidad del látex en el ensayo con A. salina se estimó mediante la CL50 usando Probit

1 Engenharia de Alimentos, Universidade Federal do Agreste de Pernambuco (UFAPE), iris.barbosa@ufape.edu.br

${ }^{2}$ Entomologia, Universidade Federal de Viçosa (UFV), graziela.gdal@gmail.com

${ }^{3}$ Agronomia, Universidade Federal do Agreste de Pernambuco (UFAPE), erika.valente@ufape.edu.br

${ }^{4}$ Veterinária, Universidade Federal do Agreste de Pernambuco (UFAPE), keila.moreira@ufape.edu.br

${ }^{5}$ Pós Doutora, Universidade Federal Rural de Pernambuco (UFRPE), analuporto@yahoo.com.br 
y el porcentaje de viabilidad celular se determinó para los resultados de citotoxicidad y se evaluó mediante la prueba de Dunnett. Después de 24 horas de exposición al látex, la CL50 de las larvas de A. salina se estimó en $64,22 \mathrm{mg} / \mathrm{ml}$. El látex de E. milii mantuvo la viabilidad celular sin causar hemólisis de eritrocitos, presentó una 147 ligera disminución en las células del linaje Vero (10,33\%) en la concentración de $35 \mathrm{mg} / \mathrm{mL}$ y redujo la viabilidad de los macrófagos $(26,34-45,53 \%)$ en las concentraciones utilizadas en el ensayo. Las pruebas preliminares in vitro revelaron que el látex de E. mili no presenta riesgo de toxicidad, pero se necesitan investigaciones complementares principalmente para su uso en las áreas de la salud y de los alimentos.

Palabras Clave: citotoxicidad, toxicidad, viabilidad celular, Euphorbia milii, Artemia salina.

\section{ABSTRACT}

The importance of toxic plants is not only on the risks they can cause, but also on the benefits they can provide. Among these, the latex of E. milii has molluscicidal activity, but also potential for pharmacological use and in food processing. Thus encouraging the assessment of its toxicity through essays that are necessary mainly when it comes to preliminary toxicological investigations in compliance with ethical and economic principles. In this sense, the present study aimed to evaluate the in vitro toxicity of E. milii' latex using Artemia salina as a model, and the evaluation of cytotoxicity with human erythrocytes, Vero lineage and macrophages. E. milii' latex was extracted and diluted (1/1) in $1 \mathrm{M}$ sodium phosphate buffer solution, $\mathrm{pH} 7.0$ was centrifuged $\left(5000 \mathrm{~g}, 4^{\circ} \mathrm{C}\right.$ for $30 \mathrm{~min}$.) and the final product underwent a freeze-drying process. In the toxicity essay against $A$. salina, lyophilized latex was tested at concentrations of $3.5 ; 7.0 ; 10.5 ; 14 ; 21 ; 28$ and $35 \mathrm{mg} / \mathrm{mL}$ of sterile seawater. In the cytotoxicity test, the latex was dialysed before lyophilization and diluted to the same concentrations in saline. The toxicity of the latex in the assay with A. salina was estimated by the LC50 using Probit and the percentage of cell viability was determined for the results of cytotoxicity and evaluated by the Dunnett test. After 24 hours of exposure to latex, the LC50 of A. salina larvae was estimated at $64.22 \mathrm{mg} / \mathrm{mL}$. The latex of E. milii maintained the viability of the cells without causing hemolysis of the erythrocytes, and presented a slight decrease in the cells of the Vero lineage $(10.33 \%)$ at a concentration of $35 \mathrm{mg} / \mathrm{mL}$ and reduced the viability of macrophages $(26.34-45,53 \%)$ at the concentrations used in the essay. Preliminary in vitro tests revealed that E. mili latex does not present a risk of toxicity, but further investigations are needed mainly for its use in the health and food fields.

Keywords: cytotoxicity, toxicity, cell viability, Euphorbia milii, Artemia salina.

\section{INTRODUÇÃO}

O látex de Euphorbia milii, assim como outros compostos considerados "naturais", vêm sendo estudado quanto a sua composição química e toxicidade ( LYNN; CLEVETTERADFORD, 1988; SOUZA et al., 1997; OLIVEIRA-FILHO; PAUMGARTTEN, 2000; OLIVEIRA-FILHO et al., 2012; SHAH; PARAY, 2014; PRINSLOO; STREET, 2018). Esse interesse visa atender a expectativa de buscar na natureza e nos conhecimentos populares tradicionais uma maior aplicabilidade para o uso de extratos de plantas e seus princípios ativo devido a sua disponibilidade e aceitabilidade (BERLINCK et al., 2017; FARNSWORTH et al., 1985; KAUR et al., 2005; DUTRA et al., 2016; KHALIL et al., 2014; OMOYENI et al., 2016; LIMA JUNIOR; ABREU, 2018).

E. milii também conhecida como "Coroa-de-Cristo" ou "Coroa-de-Espinhos" é facilmente cultivada em estacas, bem adaptada a solos pobres em nutrientes e resistente à escassez de água. A planta é nativa de Madagascar e seu látex é usado no controle de moluscos

e na medicina tradicional no tratamento de fígado e esquistossomose em animais, (GONZÁLEZ-RÁBADE et al., 2011; KHALIL et al., 2014), mas na China foi usado para tratamento de hepatite e edema abdominal (SOUZA et al., 1997; YADAV; PANDE; 
JAGANNADHAM, 2006). No Brasil há relatos do uso de seu látex no peeling de pele (DELGADO et al., 2003; MORO et al., 2008).

Dentre os testes in vitro, a Artemia salina é usada como referência e mantém uma boa correlação com ensaios de toxicidade em geral e anti-tumorais (MEYER et al., 1982; OLIVEIRA-FILHO; PAUMGARTTEN, 2000; SANTOS et al., 2010; ARCANJO et al., 2012;

RAUF, KHAN; UDDIN, 2013). Nesse sentido, o presente estudo objetivou avaliar a toxicidade in vitro do látex de E. milii, utilizando para tal modelos de estudos de referência e alternativos.

\section{FUNDAMENTAÇÃO TEÓRICA}

A E. milii é identificada na natureza como um arbusto perene com ramos contorcidos e numerosos espinhos, mas rico em látex. Este látex é um líquido que contém uma mistura de soro, borracha, materiais de baixa densidade (LYNN; CLEVETTE-RADFORD, 1988) e várias enzimas, dentre as quais três: miliin (serino protease), milin e eumiliim (cisteína protease) que já foram caracterizadas, quanto aos efeitos do $\mathrm{pH}$, temperatura e sua atividade proteolítica (YADAV; PANDE; JAGANNADHAM, 2006; MORO et al., 2008; FONSECA et al., 2010). Devido a estabilidade dessas macromoléculas, elas podem despertar o interesse da indústria farmacêutica, biotecnológica e alimentícia (YADAV; PANDE; JAGANNADHAM, 2006).

Nessa potencial aplicação industrial, se faz necessária pesquisar o látex de E. milii e suas enzimas para o desenvolvimento de novos produtos e emprego nos diferentes segmentos industriais.

Sufiate et al. (2017) mostraram a eficiência das proteases do látex de E. milii in vitro na mortalidade de larvas de nematoides (Panagrellus redivivus).

Recentes estudos apresentado por Okonkwo e Ohaeri (2018) utilizaram os óleos essenciais obtidos das folhas de E. milii, para testes em larvas de insetos e encontraram fortes evidências para mostrar que os extratos podem exercer ação como inseticida classificado como organoclorados em função da sua ação fisiológica

Em camundongos fêmeas, Sreenika et al. (2015) induziram linhagens de células cancerígenas, trataram os animais com o extrato da flor de E. milii em acetato de etila e depois avaliaram parâmetros bioquímicos, parâmetros específicos de câncer (antígeno embrionário Ferritina e Carcino - CEA) e laudos histopatológicos para revelar a sua ação eficaz como antioxidante e quimiopreventivo.

Assim como relevantes pesquisas envolvendo a toxicidade das enzimas sobre moluscos e embriões de Biomphalaria glabrata no sentido de combater os caramujos vetores da esquistossomose. (VASCONCELLOS et al., 1986; MENDES et al., 1997; OLIVEIRA-FILHO 


\section{et al., 2010; SANTOS et al., 2010; OLIVEIRA-FILHO et al., 2012; AUGUSTO et al., 2017).}

E. milii é considerada o recurso natural mais promissor apresentado pela Organização Mundial 149 de Saúde (OMS) como estratégia de controle da esquistossomose (FARNSWORTH et al., 1985; AUGUSTO et al., 2017; AUGUSTO; MELO SILVA, 2018).

No trabalho desenvolvido por Fonseca et al. (2010) uma dessas enzimas, cisteína protease (eumiliin) induziu edema, mionecrose com leucócitos infiltrados e danificou as fibras musculares na pata do camundongo após injeção intraplantar. Delgado et al. (2003) estudaram compostos fitoquímicos de E. milli e identificaram a presença de $\beta$-sitosterol, cicloartenol, acetato de $\beta$-amirina, lupeol, eufol, triterpenos e flavonóides.

Por outro lado, Venkatesha e Vishwanath (2016) relataram que não tem sido observado nenhum efeito tóxico para serino proteases isoladas de látex de plantas e que esses efeitos são principalmente devidos a outras substâncias presentes nos mesmos. Entre essas, os diterpenos, que causam efeitos adversos como irritação da pele com formação de bolhas, inflamação e alterações carcinogênicas. (MOREIRA et al., 2014; PRINSLOO; NOGEMANE; STREET, 2018).

Diante do exposto, fica claro a necessidade de conhecer não somente os potenciais usos industriais, mas em princípio, os possíveis efeitos tóxicos do látex de E. milli. Considerando as razões éticas e econômicas o uso de animais deve ser evitado quando se trata de investigações toxicológicas preliminares, dando assim ênfase à utilização de modelos experimentais in vitro de referência ou alternativos. O uso de células humanas e de animais é um sistema alternativo para testes toxicológicos de diferentes classes de produtos sintéticos e naturais (KRISTEN, 1997; LIMA et al., 2018).

Os testes in vitro podem ser realizados com bactérias, fungos, algas e crustáceos, além de frações subcelulares presentes no sistema biológico como suspensões celulares, cultivo de tecidos, cultivos celulares, enzimas e proteínas. Contudo, os estudos com cultura de células vêm se destacando dentre os demais (FRAZIER, 1992; BEDNARCZUK et al, 2010).

\section{METODOLOGIA}

A pesquisa é quantitativa com ensaio experimental no campo das ciências biológicas envolvendo material coletado da flora do Brasil e seguindo protocolos de testes in vitro de toxicidade.

\section{Coleta do material vegetal}


As plantas de Euphorbia milii Des Moulins foram localizadas em Garanhuns Pernambuco (GPS $08^{\circ} 53^{\prime} 26^{\prime}$ 'S e 36 $29^{\prime} 47^{\prime}$ ' W) para a coleta do látex no período de maio a julho de 2017. Amostra representativa da planta foi encaminhada para classificação e depositado no herbário Dárdano de Andrade Lima, sob o número 91595, do Instituto Pernambucano de Agronomia (IPA).

A coleta do látex de E. mili foi realizada higienicamente protegido com luvas descartáveis e material cortante em inox e pinça para remoção das sujidades. A coleta foi realizada diretamente em tubos plásticos tipo Falcon de $15 \mathrm{~mL}$ com identificação de volume até atingir $4 \mathrm{~mL}$ e em seguida completados com $4 \mathrm{~mL}$ de solução tampão fosfato de sódio $1 \mathrm{M}$, pH 7,0. O látex adicionado do tampão foi homogeneizado e acondicionado em caixa isotérmica mantendo a temperatura de $8{ }^{\circ} \mathrm{C}$ para transporte até o laboratório. Os tubos com o látex homogeneizados foram identificados e congelados em freezer da Bosch $^{\circledR}$ a temperatura de ($20{ }^{\circ} \mathrm{C}$ ) até o desenvolvimento do experimento.

\section{Preparação do látex de Euphorbia milii}

O látex homogeneizado passou por duas etapas de centrifugação a 5000 . g e $4{ }^{\circ} \mathrm{C}$ por 30 minutos para remover partículas maiores e concentrar as enzimas. Em seguida, o líquido sobrenadante límpido contendo as enzimas foi separado e transportado para um novo tubo de plástico tipo Falcon de $15 \mathrm{~mL}$ e repetida a mesma centrifugação e as partículas sedimentadas foram removidas e descartadas. Em seguida, o látex de E. mili foi pipetado (1mL), distribuído em microtubos eppendorf e armazenados em ultra-congelador Eletrolux ${ }^{\circledR}\left(-70{ }^{\circ} \mathrm{C}\right)$ por 24 horas para liofilização.

No teste de toxicidade in vitro com A. salina foi utilizado o látex liofilizado e no ensaio de citotoxicidade o látex passou também pelo processo de diálise em água pdeionizada por 24 horas sob refrigeração na geladeira da $\operatorname{Bosch}^{\circledR}\left(8^{\circ} \mathrm{C}\right)$ antes da etapa de liofilização realizada em Liofilizador Terroni ${ }^{\circledR}$. Após essa etapa as amostras liofilizados/dialisadas foram armazenadas sob congelamento em freezer da $\operatorname{Bosch}^{\circledR}\left(-20^{\circ} \mathrm{C}\right)$ para posterior realização dos ensaios.

\section{Toxicidade do látex de Euphorbia milii in vitro}

Nos testes de toxicidade in vitro, incialmente foi preparada uma solução padrão resuspendendo $70 \mathrm{mg}$ de látex liofilizado/dialisado em $1 \mathrm{~mL}$ de água do mar esterilizada para exposição das A. salina ou $1 \mathrm{~mL}$ de soro fisiológico para avaliação de viabilidade dos eritrócitos humanos e das células de linhagens Vero e de macrófagos. Na realização dos ensaios a solução foi preparada nas concentrações de 3,5 mg/mL (5\%); $7 \mathrm{mg} / \mathrm{mL}(10 \%) ; 10,5 \mathrm{mg} / \mathrm{mL}$ (15\%), 14 
$\mathrm{mg} / \mathrm{mL}(20 \%) ; 21 \mathrm{mg} / \mathrm{mL}$ (30\%); $28 \mathrm{mg} / \mathrm{mL}(40 \%)$ e $35 \mathrm{mg} / \mathrm{mL}$ (50\%) para os testes com $A$. salina e citotoxicidade.

\section{Primeiro teste: Obtenção e ensaio de sobrevivência da Artemia salina}

A. salina em forma de cistos (embalagem de $5 \mathrm{~g}$ ) foi adquirida em casa de alimentação animal e ativada na proporção de $25 \mathrm{mg}$ em $500 \mathrm{~mL}$ de água do mar com pH 8,44 e temperatura de 25-30 ${ }^{\circ} \mathrm{C}$. A água do mar foi coletada no litoral de Recife-Pernambuco e esterilizada a (121/15 ${ }^{\circ}$ C). A eclosão da A. salina ocorreu com aeração por 48 horas e em ambiente adaptado com foto-controle.

Após a eclosão, as larvas viáveis foram divididas em microplaca para cultura celular em nove grupos, sendo sete para testar as concentrações do látex de E. milii, um controle positivo que foi feito com um sal de dicromato de potássio $\left(\mathrm{K}_{2} \mathrm{Cr}_{2} \mathrm{O}_{7}\right)$ diluído a 20 ppm em água do mar e um controle negativo apenas água marinha. Em cada grupo continha 24 a 37 unidades de $A$. salina para exposição nas concentrações do ensaio. (MEYER, et al, 1982). As larvas foram expostas ao látex de E. milii nas concentrações de 3,5 mg/mL até $35 \mathrm{mg} / \mathrm{mL}$ (50\%).

$\mathrm{Na}$ avaliação de sobrevivência e mortalidade os animais vivos ou em óbitos foram contados e os resultados analisados no programa Probit usando o software SPSS ${ }_{1} 19.0$ (IBM® Corp., NY, EUA), obtendo-se o valor de CL50 com um intervalo de confiança de 95\% (SANTOS et al., 2010)

\section{Segundo teste: Ensaio de hemólise}

Este ensaio foi realizado para determinar a compatibilidade de eritrócitos humanos com o látex de E. milii. O sangue humano fresco foi coletado, centrifugado a 700. g por 10 min., lavado três vezes com tampão fosfato-salino (PBS $10 \mathrm{mM}$; $\mathrm{NaCl} 137 \mathrm{mM}, \mathrm{KCl}$ 2,7 mM, $\mathrm{Na}_{2} \mathrm{HPO}_{4} 10 \mathrm{mM}, \mathrm{KH}_{2} \mathrm{PO}_{4} 2 \mathrm{mM}, \mathrm{pH}$ 7,4) e ressuspenso no mesmo tampão para preparar a suspensão de glóbulos vermelhos a 2\% (XU et al., 2017). Posteriormente, 3,5 até $35 \mathrm{mg} / \mathrm{mL}$ (50\%) do látex foram incubadas com a suspensão de hemácias a $37{ }^{\circ} \mathrm{C}$.

As hemácias também foram incubadas com tampão fosfato-salino e Triton X-100 (1\% v/v) como controle negativo e positivo, respectivamente. Após 24 h, as amostras foram centrifugadas por 10 min a 700g (XU et al., 2017) e determinou-se a liberação de hemoglobina com auxílio de um leitor de microplaca (SpectraMax M5, Molecular Devices) a $540 \mathrm{~nm}$.

O percentual de hemólise foi determinado pela seguinte equação:

$\%$ de hemólise $=\underline{\text { absorbância da amostra x } 100}$ absorbância do controle positivo 
Os procedimentos descritos acima estão de acordo com os princípios éticos de pesquisa (protocolo número 108/2012/CEPH/wmt).

\section{Terceiro teste: Viabilidade celular em dois tipos de linhagens celulares e cultivo celular}

Células das linhagens Vero (rim de macaco) e de macrófago (RAW 264.7) foram 152 gentilmente cedidas pela Prof ${ }^{a}$ Dra. Juliana Lopes Rangel Fietto (Departamento de Bioquímica e Biologia Molecular, UFV, Viçosa, Minas Gerais, Brasil), as mesmas foram cultivadas, mantidas em meio RPMI 1640, pH 7,2 (Gibco, Invitrogen, CA, USA) e suplementadas com $10 \%$ de soro fetal bovino (10\% SFB), penicilina (1\%), estreptomicina $(1 \%)$ a $37^{\circ} \mathrm{C}$, sob tensão de $5 \%$ de $\mathrm{CO}_{2}$. Antes de cada experimento, as células foram removidas das garrafas de cultivo com auxílio de tripsina $(0,25 \%)$, centrifugadas (1500 rpm; 5 minutos) e ressuspensas em meio RPMI 1640, sendo suplementadas com SFB. Em seguida, essas células foram contadas em câmara de Neubauer e semeadas em placas de 96 poços, respeitando-se as concentrações celulares adequadas para cada ensaio (LIMA et al., 2018).

A viabilidade celular de duas linhagens celulares frente ao látex de E. milii foi determinada pelo ensaio de MTT (brometo de (3- (4,5 dimetiltiazol-2-il)-2,5-difeniltetrazólio; Sigma) previamente descrito (PIETRASZEK et al., 2013). As linhagens Vero $\left(3 \times 10^{4}\right.$ células/poço) e macrófago ( $5 \times 10^{4}$ células/poço) foram incubadas em placas de 96 poços, por 24 horas a $37^{\circ} \mathrm{C}$ e $5 \%$ de $\mathrm{CO}_{2}$. Cada poço continha $100 \mu \mathrm{L}$ de meio RPMI completo e $100 \mu \mathrm{L}$ do látex de E. milii nas concentrações de 3,5 mg/mL (5\%) até $35 \mathrm{mg} / \mathrm{mL}$ (50\%) diluídos em meio RPMI com $10 \%$ de SFB.

Após 48 de incubação, MTT (5 mg/mL, Sigma) foi adicionado em cada poço. Após $4 \mathrm{~h}$ a $37^{\circ} \mathrm{C}$, a solução de MTT foi removida e $100 \mu \mathrm{l}$ de DMSO foi adicionado um cada poço para solubilizar os cristais de formazan. A absorbância foi lida a $540 \mathrm{~nm}$ em um leitor de microplaca (SpectraMax M5, Molecular Devices).

Os resultados foram normalizados considerando os poços tratados com meio RPMI (controle). Para os cálculos da viabilidade celular foi utilizada a seguinte equação: \% de viabilidade $=($ absorbância da amostra x 100)/absorbância do controle (RPMI) $)$.

\section{RESULTADOS E DISCUSSÃO}

O ensaio com $A$. salina foi realisado como triagem para medir o gráu de toxicidade do látex de E. mili e serviu de parâmetro na busca dos testes de citotoxicidade para dar continuidade na avaliaçao da sua segurança. Os resultados do bioensaio com A. salina, um microcrustáceo usado no teste de toxicidade do látex liofilizado de E. milii estão apresentados na Tabela 1. 
Tabela 1. Dados de sobrevivência de Artemia salina expostas ao látex liofilizado de Euphorbia milii após 24 h de exposição.

\begin{tabular}{ccccc}
\hline $\begin{array}{c}\text { Látex } \\
{[\mathbf{m g} / \mathbf{m L}]}\end{array}$ & $\begin{array}{c}\text { Artemia } \\
\text { Salina }(\mathbf{n})\end{array}$ & \multicolumn{2}{c}{ Sobrevivência após 24 horas } \\
Vivos & Mortos & Sobrevivência $(\%)$ \\
\hline 3,5 & 37 & 35 & 2 & 94,60 \\
7,0 & 28 & 26 & 2 & 92,86 \\
10,5 & 30 & 27 & 3 & 90,00 \\
14,0 & 33 & 29 & 4 & 87,88 \\
21,0 & 33 & 28 & 5 & 84,84 \\
28,0 & 30 & 20 & 10 & 66,66 \\
35,0 & 30 & 17 & 13 & 56,66 \\
Controle + & 24 & 2 & 22 & 8,33 \\
Controle - & 24 & 24 & 0 & 100 \\
\hline
\end{tabular}

Fonte: Própria (2019)

Após 24 horas de exposição da $A$. salina ao látex de E. mili nas concentrações de 3,5 até $21 \mathrm{mg} / \mathrm{mL}$ as larvas sobreviveram com leve redução de $94,60 \%$ até $84,84 \%$, respectivamente. Mas nas concentrações maiores $28 \mathrm{mg} / \mathrm{mL}$ (40\%) e $35 \mathrm{mg} / \mathrm{mL}$ (50\%) o meio ficou turvo com formação de uma pequena película na superfície e foram observadas as maiores reduções na sobrevivência das larvas de 66,66\% e 56,66\%, respectivamente. Esse resultado encontrado pode ser interpretado pela exposição das larvas a alta concentração do látex, ou outros compostos ativos presentes no látex ou até mesmo resíduos das larvas mortas que não sobreviveram e que permaneceram no mesmo local. $\mathrm{O}$ índice de mortalidade das larvas após 24 horas no bioensaio de toxicidade do látex de E. milii sobre A. salina foi estimado por meio do cálculo da $\mathrm{CL}_{50}$, obtendo-se o valor de $64,22 \mathrm{mg} / \mathrm{mL}$ ou $64220 \mu \mathrm{g} / \mathrm{mL}$. Esse resultado pode considerar o látex de E. milii como composto não tóxico segundo Meyer et al. (1982). Na metodologia proposta (MEYER et al., 1982) foi estabelecido uma relação entre o grau de toxicidade e a dose letal média, $\mathrm{CL}_{50}$, de extratos de plantas sobre microcrustáceos A. salina, considerando que quando verificados valores acima de $1000 \mu \mathrm{g} / \mathrm{mL}$ e não havendo morte acima de 50\%, estes, são considerados atóxicos.

$\mathrm{O}$ resultado encontrado nesse trabalho de $\mathrm{CL}_{50}=64,22 \mathrm{mg} / \mathrm{mL}$ difere dos dados encontrados por Oliveira-Filho e Paumgartten, (2000), que analisaram o látex bruto de E. milii e encontraram $\mathrm{CL}_{50}=24,23 \mathrm{mg} / \mathrm{L}(0,024 \mathrm{mg} / \mathrm{mL})$ em 24 horas para o tempo de exposição de larvas de Artemia sp nauplii. A diferença nos resultados pode estar na forma de preparo do látex para realizar os ensaios. Nesse trabalho o látex foi coletado e misturado na mesma proporção com solução tampão fosfato de sódio $1 \mathrm{M}, \mathrm{pH}$ 7,0 e após duplo processo de centrifugação foi usado somente a parte aquosa sobrenadante com descarte de todo material tipo borracha decantado no tubo de plástico. No processo de centrifugação e diálise, segundo Ramos et al. (2006) as principais proteínas solúveis são facilmente separadas da borracha e compostos de 
baixo peso molecular que podem causar maior toxicidade. No caso de Oliveira-Filho e Paumgartten, (2000) foi utilizado o látex bruto, da forma que foi coletado e liofilizado para uso no ensaio.

No ensaio de citotoxicidade o látex de E. milii foi dialisado seguindo metodologia de Fonseca et al., (2010) antes de ser liofilizado. Inicialmente foi realizado o ensaio do látex de $E$. milii frente a eritrócitos primários humanos (Figura 1) e duas diferentes linhagens de células de mamífero (Figura 2 e 3).

Figura 1- Gráfico representativo do teste de hemólise do efeito do extrato enzimático de Euphorbia milii sobre eritrócitos primários. Valores expressos como média \pm S.E.M. $* P<0,05$ pelo teste de Dunnett. n.s: não significativo. Controle positivo $(\mathrm{C}+)$ : Triton X-100, indicando hemólise total. Controle negativo (C-): tampão fosfato-salino, hemólise basal.

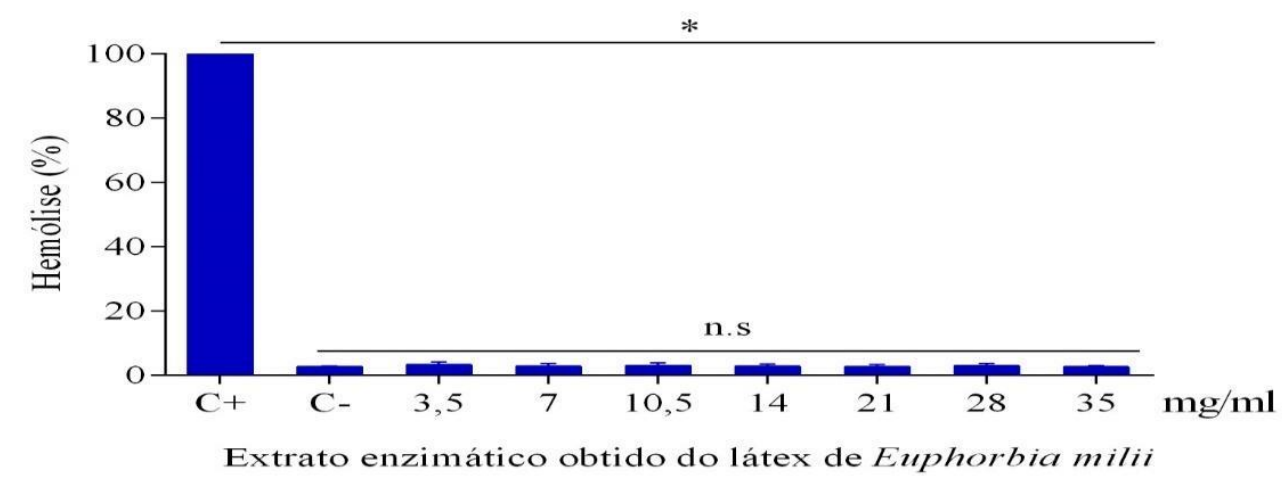

Fonte: Própria (2019)

O ensaio de hemólise mostrou que o látex de E. milii nas concentrações e condições experimentais utilizadas não causou hemólise, visto que não houve diferença significativa entre as concentrações do látex e o controle negativo.

Figura 2- Gráfico representativo do teste de MTT do efeito do extrato enzimático de Euphorbia milii sobre a linhagem Vero. Dados expressos como média \pm S.E.M. $* P<0,05$ : concentrações do látex versus controle (RPMI) pelo teste de Dunnett.

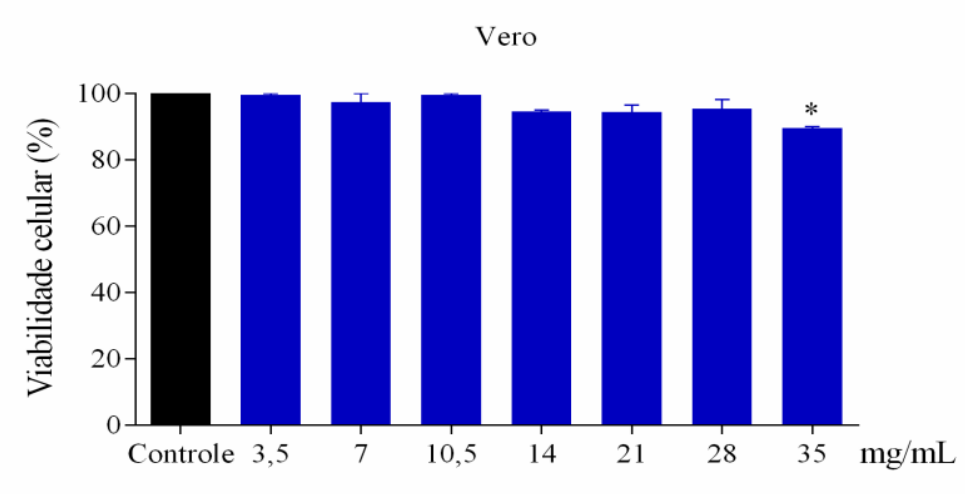

Extrato enzimático obtido do látex de Euphorbia milii

Fonte: Própria (2019)

No que se refere à viabilidade celular, a linhagem Vero foi ligeiramente sensível ao látex de E. milii apenas na concentração de $35 \mathrm{mg} / \mathrm{mL}$ (10,33\%; Figura 2). Esse resultado pode 
indicar que o látex de E. milii não cause resposta direta sobre linhagens celulares menos reativas (i.e., menos sensíveis ou suceptíveis).

Figura 3- Gráfico representativo do teste de MTT do efeito do extrato enzimático de Euphorbia milii sobre macrófagos. Gráfico representativo do teste de MTT. Dados expressos como média \pm S.E.M. $* P<0,05$ : concentrações do látex versus controle (RPMI) pelo teste de Dunnett.

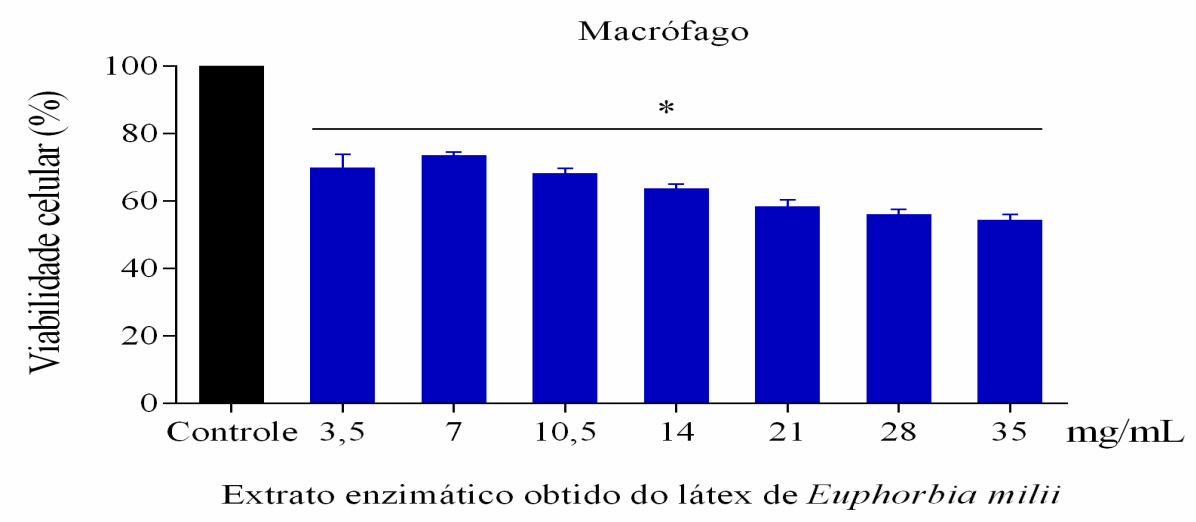

Fonte: Própria (2019)

No entanto é importante notar que o látex de E. milii pode causar significativa resposta em células mais reativas (i.e., relacionados à resposta inflamatória) como macrófagos (Figura 3). Todas as concentrações do látex foram capazes de reduzir a viabilidade celular da linhagem de macrófago de 26,34\% na concentração de $7 \mathrm{mg} / \mathrm{mL}$ mas atingindo o máximo de 45,53\% na concentração de $35 \mathrm{mg} / \mathrm{mL}$. Esse resultado indica que componentes presentes no látex de $E$. milii podem modular respostas fisiológicas relacionada com a sensibilidade. Resposta similar observada por Fonseca et al., (2010), que em estudo in vivo usaram o látex de E. milii liofilizado e também dialisado para extrair a eumiliin (cisteína protease) para avaliar e caracterizar os efeitos da enzima ao aplicarem injeção intraplantar na pata de camundongos. Eles realizaram análises histopatológicas e observaram a formação de edema com infiltrado leucocitário visível e a alta presença de macrófagos sugerindo que a eumiliin presente no látex de E. milii pode causar perturbações teciduais em camundongos, mas não sem evidências de lesões vasculares ou hemorrágicas. Estes autores também ressaltaram que existe pouca informação disponível sobre as atividades bioquímicas presentes no látex de E. milii, mostrando a importância de pesquisar esses efeitos, tanto pelo seu uso na medicina tradicional como possíveis aplicação na indústria farmacêutica e de alimentos. No resultado de citotoxicidade em relação aos macrófagos evidencia a presença da eumiliin como uma das proteases presentes no látex de $E$. milii e com atividade sobre a caseína, evidenciada na patente de processo de obtenção de um novo coagulante de leite a partir do látex da "Coroa de Cristo" para processamento de queijos (Souza et al., 2018). 


\section{CONCLUSÕES}

O látex de E. milii analisado in vitro mantem a viabilidade das larvas de A. salina e das células nas concentrações e condições experimentais utilizadas nos ensaios. As larvas de $A$. salina apresentam baixa mortalidade após 24 horas de exposição ao látex de E. milii e o índice de mortalidade das larvas no bioensaio de toxicidade é estimado em $\mathrm{CL}_{50}=64,22 \mathrm{mg} / \mathrm{mL}$. O látex de E. milii não causa hemólise frente a eritrócitos primários humanos, a linhagem Vero apresenta ser ligeiramente sensível apenas na concentração de $35 \mathrm{mg} / \mathrm{mL}(10,33 \%)$ e na linhagem de macrófago a viabilidade é reduzida em todas as concentrações usadas no ensaio atingindo o máximo de 45,53\% na maior concentração de $35 \mathrm{mg} / \mathrm{mL}$. Os testes preliminares in vitro revelam que o látex de E. mili não apresenta risco de toxicidade mas são recomendados dados farmacocinéticos para substâncias isoladas ou concentradas cujo metabolismo não é conhecido.

\section{REFERÊNCIAS}

ARCANJO, D.D.R., et al. Bioactivity evaluation against Artemia salina Leach of medicinal plants used in Brazilian Northeastern folk medicine. Brazilian Journal Biology, v. 72, n. 3, p. 505-509, 2012.

ANVISA. Guia para Comprovação da Segurança de Alimentos e Ingredientes. Brasil Anvisa, p. 45, 2013. Disponível em: 〈http://nutrimialimentos.com.br/guia.pdf〉.

AUGUSTO, R.C. et al. Double impact: natural molluscicide for schistosomiasis vector control also impedes development of Schistosoma mansoni cercariae into adult parasites. PLOS Neglected Tropical Diseases, v. 11, n. 7, p. 1-19, 2017.

AUGUSTO, R. C. \& MELLO SILVA, C. C. Phytochemical molluscicides and schistosomiasis: What We Know and What We Still Need to Learn. Veterinary Sciences, v. 5, n. 4, p. 94-102, 2018.

BEDNARCZUK, V.O. et al. Testes in vitro e in vivo utilizados na triagem toxicológica de produtos naturais. Visão Acadêmica, v.11, n.2, p.43-50, 2010.

BERLINCK, R. G. S. et al. A química de produtos naturais do Brasil do Século XXI. Quimica Nova, v. 40, n. 6, p. 706-710, 2017.

DELGADO, I. F. et al. Absence of tumor promoting activity of Euphorbia milii latex on the mouse back skin. Toxicology Letters, v. 145, n. 2, p. 175-180, 2003.

DUTRA, R. C. et al. Medicinal plants in Brazil: Pharmacological studies, drug discovery, challenges and perspectives. Pharmacological Research, v. 112, p. 4-29, 2016.

FARNSWORTH, N. R. et al. Medicinal plants in therapy. Bulletin of the World Health Organization, v. 63, n. 6, p. 965-981, 1985.

FONSECA, K. C. et al. Purification and biochemical characterization of eumiliin from Euphorbia milii var. hislopii latex. Phytochemistry, v. 71, n. 7, p. 708-715, 2010. 
FRAZIER, J. M. In vitro toxicity testing. Applications to safety evaluation. New York, Marcel Dekker, Inc., 1992. p. 300.

GONZÁLEZ-RÁBADE, N. et al. Production of plant proteases in vivo and in vitro - A review. Biotechnology Advances, v. 29, n. 6, p. 983-996, 2011.

LIMA JUNIOR, R.N.; ABREU, F.O.M.S. Produtos naturais utilizados como coagulantes e floculantes para tratamento de águas : uma revisão sobre benefícios e potencialidades. Revista Virtual de Química, v. 10, n. 3, p.1-27, 2018.

KAUR, S. et al. The in vitro cytotoxic and apoptotic activity of Triphala - An Indian herbal drug. Journal of Ethnopharmacology, v. 97, n. 1, p. 15-20, 2005.

KHALIL, A. T. et al. Phyto-therapeutic claims about Euphorbeaceous plants belonging to Pakistan; an ethnomedicinal review. Pakistan Journal of Botany, v. 46, n. 3, p. 1137-1144, 2014.

KRISTEN, U. Use of higher plants as screens for toxicity assessment. Toxicology in vitro, United Kingdom, v.11, p.181-191, 1997.

LIMA et al. Synthesis and antimetastatic activity evaluation of cinnamic acid derivatives containing 1,2,3-triazolic portions. Toxicology in Vitro, v. 53, p 1-9, 2018.

LYNN, K. R.; CLEVETTE-RADFORD, N. A. Proteases of euphorbiaceae. Phytochemistry, v. 27, n. 1, p. 45-50, 1988.

MENDES, N. M. et al. Evaluation of the molluscicidal properties of Euphorbia splendens var. hislopii (N.E.B.) Latex: Experimental test in an endemic area in the state of Minas Gerais, Brazil. Instituto Oswaldo Cruz, v. 92, n. 5, p. 719-724, 1997.

MEYER, B. N. et al. Convenient general biossay for active plant constituents. Medicinal Plant Research, v.45p.31-34, 1982.

MOREIRA, D. D. L. et al. Traditional use and safety of herbal medicines. Brazilian Journal of Pharmacognosy, v. 24, n. 2, p. 248-257, 2014.

MORO, L. P. et al. Purification, biochemical and functional characterization of miliin, a new ThiolDependent serine protease isolated from the latex of Euphorbia milii.. Protein \& Peptide Letters, v. 15, n. 7, p. 724-730, 2008.

OKONKWO, C. O.; OHAERI, O. C. Essential oils from the leaves of Euphorbia Milieu exert insecticidal activity through disruption in ionic composition. Journal of Pharmacy and Biological Sciences, v. 13, n. 4, p. 46-53, 2018.

OLIVEIRA-FILHO, E. C. et al. Absence of antimicrobial activity of Euphorbia milii molluscicidal latex. Journal of Pharmaceutical Negative Results, v. 3, n. 1, p. 13, 2012.

OLIVEIRA-FILHO, E. C. et al. Chemosphere comparative toxicity of Euphorbia milii latex and synthetic molluscicides to Biomphalaria glabrata embryos. Chemosphere, v. 81, n. 2, p. 218-227, 2010.

OLIVEIRA-FILHO, E. C.; PAUMGARTTEN, F. J. R. Toxicity of Euphorbia milii latex and niclosamide to snails and nontarget aquatic species. Ecotoxicology and Environmental Safety, v. 46, n. 3, p. 342-350, 2000. 
OMOYENI, O. A. et al. A review of the ethnomedicinal uses, phytochemistry and pharmacology of the Pleiocarpa genus. Phytochemistry Reviews, v. 6, n. 1, p. 1-19, 2016.

PIETRASZEK et al. Lumican - Derived peptides inhibit melanoma cell growth and migration. Plos One, v.8, n.13, p.1-11, 2013.

PRINSLOO, G.; NOGEMANE, N.; STREET, R. The use of plants containing genotoxic carcinogens as foods and medicine. Food and Chemical Toxicology, v. 116, n. March, p. 27-39, 2018.

RAUF, A.; KHAN, A.; UDDIN, N. Cytotoxic study of aerial parts of Euphorbia Milli and Euphorbia pulcherrima. Topclass Journal of Herbal Medicine, v.2, n. 12, p. 266-269, 2013.

SANTOS, A. F. DOS et al. Toxicity of some glucose/mannose-binding lectins to Biomphalaria glabrata and Artemia salina. Bioresource Technology, v. 101, n. 2, p. 794-798, 2010.

SCHALL, V.T. et al. Evaluation of the genotoxic activity and acute toxicity of Euphorbia splendens lates, a molluscicide for the control of schistosomiasis. Brazilian Journal Medician Biology, n.24, p.573-582, 1991.

SHAH, M. A.; MIR, S. A.; PARAY, M. A. Plant proteases as milk-clotting enzymes in cheesemaking: A review. Dairy Science and Technology, v. 94, n. 1, p. 5-16, 2014.

SOUZA, C. A. M. et al. Study of the embryofeto-toxicity of Crown-of-Thorns (Euphorbia milii) latex, a natural molluscicide. Brazilian Journal of Medical and Biological Research, v. 30, n. 11, p. 1325$1332,1997$.

REENIKA, G. et al. Antioxidant and antitumor activity of Euphorbia milii flower extract against in vivo breast cancer and colon cancer in mice. Journal of Pharmacy and Pharmaceutical Sciences, v. 4, n. 06, p. 912-934, 2015.

SUFIATE, B. L. et al. Nematicidal activity of proteases from Euphorbia milii. Biocatalysis and Agricultural Biotechnology, v. 10, n. 12, p. 239-241, 2017.

VASCONCELLOS, M, C. \& S. Latex of "Coroa de Cristo" (Euphorbia splendens) an effective moluuscicide. Mem. Insti. Osvaldo Cuz, v. 81, n. 4, p. 475-476, 1986.

VENKATESHA, S. H.; VISHWANATH, R. R.; BANNIKUPPE, S. V. Hemostatic interference of plant latex. Journal of Clinical Pathology, v. 1, n. 1, p. 1-7, 2016.

XU, T. et al. Novel electrochemical immune sensor based on Hep-PGA-PPy nanoparticles for detection of $\alpha$-Fetoprotein in whole blood. Manuscripty. Analytica Chimica Acta, p. 1-40, 2017.

YADAV, S. C.; PANDE, M.; JAGANNADHAM, M. V. Highly stable glycosylated serine protease from the medicinal plant Euphorbia milii. Phytochemistry, v. 67, n. 14, p. 1414-1426, 2006.

ZAMITH, H. P.S.; PAUMGARTTEN, F. J. R.; SPEIT, G. Evaluation of the mutagenicity of the molluscicidal latex of Christ's Crown (Euphorbia milii var. hislopii) in mammalian cells in vitro and in vivo. Mutation Research, v. 368, p.15-20, 1996. 